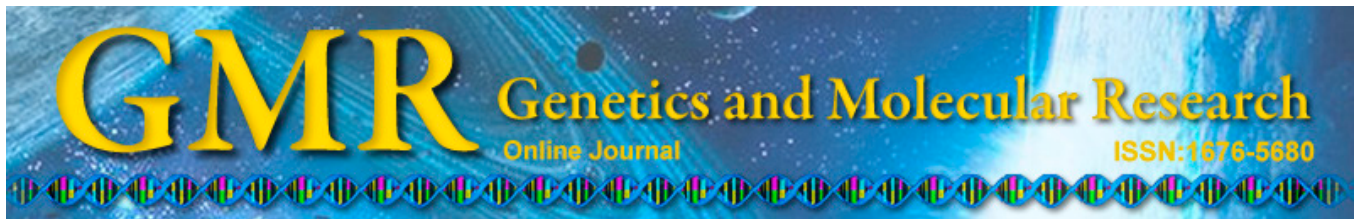

\title{
Association between SNPs in genes involved in folate metabolism and preterm birth risk
}

\author{
B.J. Wang ${ }^{1 *}$, M.J. Liu ${ }^{1 *}$, Y. Wang ${ }^{1}$, J.R. Dai ${ }^{1}$, J.Y. Tao ${ }^{1}$, S.N. Wang ${ }^{2}$, \\ N. Zhong ${ }^{3}$ and Y. Chen ${ }^{2}$ \\ ${ }^{1}$ Department of Gynaecology and Obstetrics, \\ Center for Reproduction and Genetics, \\ Suzhou Hospital Affiliated to Nanjing Medical University, Suzhou, China \\ ${ }^{2}$ Department of Neonatology, Central Laboratory, \\ Suzhou Hospital Affiliated to Nanjing Medical University, Suzhou, China \\ ${ }^{3}$ Center of Medical Genetics, Peking University, Beijing, China \\ *These authors contributed equally to this study. \\ Corresponding author: Y. Chen \\ E-mail: cyandzh@sohu.com
}

Genet. Mol. Res. 14 (1): 850-859 (2015)

Received November 21, 2013

Accepted October 28, 2014

Published February 2, 2015

DOI http://dx.doi.org/10.4238/2015.February.2.9

\begin{abstract}
We investigated the association between 12 single nucleotide polymorphisms (SNPs) in 11 genes involved in folate metabolic and preterm birth. A subset of SNPs selected from 11 genes/ loci involved in the folic acid metabolism pathway were subjected to SNaPshot analysis in a case-control study. Twelve SNPs (CBS-C699T, DHFR-c594+59del19, GST01-C428T, MTHFD-G1958A, MTHFRC677T, MTHFR-A1298C, MTR-A2756G，MTRR-A66G，NFE2L2ins1+C11108T, RFC1-G80A, TCN2-C776G, and TYMS-1494del6) in 503 DNA samples were simultaneously tested, and included 315 preterm births and 188 controls. None of the 12 SNP genotype distributions related to the folic acid metabolism pathway showed a significant difference between preterm and term babies. The frequency of the compound mutation genotype of MTHFD-G1958A, MTR-A2756G and $R F C 1-\mathrm{G} 80 \mathrm{~A}$ in preterm babies was $7.3 \%$, which was significantly
\end{abstract}


higher than the $2.7 \%$ in term babies. Seven babies carried the compound mutation genotype of MTHFD-G1958A, MTR-A2756G, and CBSC699T, but this was not observed in term babies. The frequency of the combined wild-type genotype of MTHFD-G1958A, MTR-A2756G, MTRR-A66G, MTHFR-A1298C, NFE2L2-ins1+C11108T, and RFC1G80A in preterm babies was $3.17 \%$, which was significantly lower than the $7.4 \%$ in term babies. The 12 SNPs screened in this study were not independent risk factors of preterm birth. Compound mutation genotypes, including MTHFD-G1958A, MTR-A2756G, and RFC1G80A and MTHFD-G1958A, MTR-A2756G, and CBS-C699T, may increase the risk of preterm birth. The combined wild-type genotype MTHFD-G1958A，MTR-A2756G，MTRR-A66G，MTHFR-A1298C, NFE2L2-ins1+C11108T, and RFC1-G80A may decrease the risk of preterm birth.

Key words: Folate metabolism; Folic acid; Preterm birth; Single nucleotide polymorphism

\section{INTRODUCTION}

Preterm birth (PTB; birth before 37 weeks in humans) is one of the most common disorders threatening perinatal health. The prevalence of PTB continues to increase. A study of 1,112,897 newborns in 155 large hospitals in 23 provinces and cities from 2005 to 2009 revealed that the 5-year average prevalence of preterm birth was $5.5 \%$ in China according to the Chinese Preterm Clinical Research Consortium.

PTB is the leading cause of infant death in China. Prematurity is associated with $75 \%$ of cases of infant mortality and 50\% of long-term neurological handicaps, including blindness, deafness, developmental delay, cerebral palsy, and chronic lung disease. The etiologies of most preterm births remain unknown. Various factors have been associated with an increased risk for preterm delivery, including maternal anthropometrics, health and age, prenatal care, and socioeconomic status; however, none of these factors have been found to entirely and adequately explain the cause of preterm birth (Han et al., 2011) .

In a cohort of 34,480 singleton pregnancies, preconceptional folate supplementation was found to be associated with a $50-70 \%$ reduction in the incidence of early spontaneous PTB (Bukowski et al., 2009). Additionally, hyperhomocysteinemia was found to be associated with preterm birth in mice (Sonne et al., 2013). Growing evidence suggests that genes related to the folate metabolism pathway are involved in PTB and that their possible roles in PTB are likely complicated by interactions with dietary habits. Previous reports demonstrated that serine hydroxymethyltransferase $1 \mathrm{C} 1420 \mathrm{~T}, \mathrm{~N}^{5}, \mathrm{~N}^{10}$-methylenetetrahydrofolate reductase (MTHFR) C677T, and A1298C may be associated with a high risk of PTB (Chen et al., 2004; Valdez et al., 2004; Engel et al., 2006). However, no case-control studies have been conducted to determine genotype frequencies using the SNaPshot method among PTB cases to investigate the association between genetic variants in folate and the 1-carbon metabolic pathway and PTB. 


\section{MATERIAL AND METHODS}

A total of 503 subjects were enrolled in this study and provided informed consent, including 315 cases of preterm babies and 188 normal in-term babies who were born in the Suzhou Maternal-Child Medical Center from 2008 to 2011. DNA from 315 preterm babies was extracted from blood spots using an NP968 automatic nucleic acid extraction apparatus, which was originally used for neonatal screening for genetic metabolism diseases; DNA samples from 188 in-term babies were extracted from cord blood using the Qiagen DNA Blood Mini Kit (Hilden, Germany). The study was approved by the Ethics Committee for Human Research, Suzhou Hospital Affiliated to Nanjing Medical University.

\section{Genotyping}

To understand the specific role of SNPs in genes involved in folate metabolis in PTB, 12 candidate SNPs in 11 genes were genotyped using the SNaPshot method. The protocol for the SNaPshot method has been published elsewhere (Bardien et al., 2009; Wu et al., 2009) and was used with some modifications (Wang et al., 2013). The primers were synthesized by the Shanghai Genearray Company in China.

\section{Statistical analysis}

Statistical tests were performed, including the $\chi^{2}$ test and binary logistic analysis, using the SPSS software (17.0) for Windows. Odds ratios (ORs) and 95\% confidence intervals (CIs) were calculated when $\mathrm{P}<0.05$ was considered to be statistically significant.

\section{RESULTS}

\section{Genotype distribution}

We screened 12 candidate SNPs in 11 genes involved in folate metabolism to determine their association with preterm birth in 315 PTB babies and 188 term babies using the SNaPshot method. The genotype frequencies of the 12 SNPs were in agreement with Hardy-Weinberg equilibrium. Data regarding genotype distributions are shown in Table 1. The mutation frequencies in the 12 SNPs showed no significant differences between preterm and term babies, although the mutation frequencies in some SNPs were lower in preterm babies, including MTHFD-G1958A, MTHFR-C677T, MTRR-A66G, CBS-C699T, MTHFR-A1298C, DHFR-c594+59del19, and TYMS-1494del6. Additionally, the mutation frequencies of several SNPs were higher in PTB babies, including MTR-A2756G, NFE2L2-ins1+C11108T, RFC1G80A, GSTO1-C428T, and TCN2-C776G. These results do not support that the mutation genotypes of the 12 SNPs analyzed were independent risk factors of PTB. Binary logistic regression was used to analyze the associations between the 12 SNPs and PTB in order to eliminate the interaction effect (Table 2). Additionally, there was no evidence that the mutation genotypes increased or decreased the risk of PTB. 
Table 1. Comparison of genotype distributions of 12 SNPs in preterm and term babies.

\begin{tabular}{|c|c|c|c|c|c|c|}
\hline \multirow[t]{2}{*}{ SNPs } & \multirow[t]{2}{*}{ Genotype } & \multirow{2}{*}{$\frac{\text { Term delivery }}{\mathrm{N}=188[\mathrm{~N}(\%)]}$} & \multirow{2}{*}{$\frac{\text { Preterm delivery }}{\mathrm{N}=315[\mathrm{~N}(\%)]}$} & \multirow[t]{2}{*}{ OR } & \multirow[t]{2}{*}{$95 \% \mathrm{CI}$} & \multirow[t]{2}{*}{$P$ values } \\
\hline & & & & & & \\
\hline \multirow[t]{4}{*}{ MTHFD-G1958A (rs2236225) } & GG & $109(58.0 \%)$ & $190(60.3 \%)$ & & & \\
\hline & GA & $64(34.0 \%)$ & $107(34.0 \%)$ & 0.96 & $0.65-1.42$ & 0.833 \\
\hline & AA & $15(8.0 \%)$ & $18(5.7 \%)$ & 0.69 & $0.33-1.42$ & 0.310 \\
\hline & $\mathrm{GA}+\mathrm{AA}$ & $79(42.0 \%)$ & $125(39.7 \%)$ & 0.91 & $0.63-1.31$ & 0.605 \\
\hline \multirow[t]{4}{*}{ MTHFR-C677T (rs1801133) } & $\mathrm{CC}$ & $53(28.2 \%)$ & $108(34.3 \%)$ & & & \\
\hline & $\mathrm{CT}$ & $100(53.2 \%)$ & $142(45.1 \%)$ & 0.70 & $0.46-1.06$ & 0.089 \\
\hline & TT & $35(18.6 \%)$ & $65(20.6 \%)$ & 0.91 & $0.54-1.54$ & 0.730 \\
\hline & $\mathrm{CT}+\mathrm{TT}$ & $135(71.8 \%)$ & $207(65.7 \%)$ & 0.75 & $0.51-1.12$ & 0.156 \\
\hline \multirow[t]{4}{*}{ MTR-A2756G (rs1805087) } & AA & $153(81.4 \%)$ & $249(79.0 \%)$ & & & \\
\hline & $\mathrm{AG}$ & $33(17.6 \%)$ & $63(20.0 \%)$ & 1.17 & $0.74-1.87$ & 0.503 \\
\hline & GG & $2(1.1 \%)$ & $3(1.0 \%)$ & 0.92 & $0.15-5.58$ & 1.000 \\
\hline & $\mathrm{AG}+\mathrm{GG}$ & $35(18.6 \%)$ & $66(21.0 \%)$ & 1.16 & $0.73-1.83$ & 0.527 \\
\hline \multirow[t]{4}{*}{ NFE2L2-ins1+C11108T (rs1806649) } & $\mathrm{CC}$ & $163(86.7 \%)$ & $257(81.6 \%)$ & & & \\
\hline & $\mathrm{CT}$ & $23(12.2 \%)$ & $52(16.5 \%)$ & 1.43 & $0.85-2.43$ & 0.180 \\
\hline & TT & $2(1.1 \%)$ & $6(1.90 \%)$ & 1.90 & $0.38-9.54$ & 0.668 \\
\hline & $\mathrm{CT}+\mathrm{TT}$ & $25(13.3 \%)$ & $58(18.4 \%)$ & 1.47 & $0.89-2.45$ & 0.135 \\
\hline \multirow{4}{*}{ MTRR-A66G (rs1801394) } & AA & $105(55.9 \%)$ & $189(60.0 \%)$ & & & \\
\hline & $\mathrm{AG}$ & $71(37.8 \%)$ & $107(34.0 \%)$ & 0.84 & $0.57-1.23$ & 0.363 \\
\hline & GG & $12(6.4 \%)$ & $19(6.0 \%)$ & 0.88 & $0.41-1.88$ & 0.741 \\
\hline & $\mathrm{AG}+\mathrm{GG}$ & $83(44.1 \%)$ & $126(40.0 \%)$ & 0.84 & $0.59-1.22$ & 0.361 \\
\hline \multirow{4}{*}{$C B S-\mathrm{C} 699 \mathrm{~T}(\mathrm{rs} 234706)$} & $\mathrm{CC}$ & $175(93.1 \%)$ & $295(93.7 \%)$ & & & \\
\hline & $\mathrm{CT}$ & $13(6.9 \%)$ & $20(6.3 \%)$ & 0.91 & $0.44-1.88$ & 0.804 \\
\hline & TT & $0(0.0 \%)$ & $0(0.0 \%)$ & & - & - \\
\hline & $\mathrm{CT}+\mathrm{TT}$ & $13(6.9 \%)$ & $20(6.3 \%)$ & 0.91 & $0.44-1.88$ & 0.804 \\
\hline \multirow[t]{4}{*}{$R F C 1-\mathrm{G} 80 \mathrm{~A}(\mathrm{rs} 1051266)$} & GG & $52(27.7 \%)$ & $86(27.3 \%)$ & & & \\
\hline & GA & $103(54.8 \%)$ & $160(50.8 \%)$ & 0.94 & $0.62-1.44$ & 0.772 \\
\hline & AA & $33(17.6 \%)$ & $69(21.9 \%)$ & 1.26 & $0.74-2.17$ & 0.394 \\
\hline & $\mathrm{GA}+\mathrm{AA}$ & $136(72.3 \%)$ & $229(72.7 \%)$ & 1.02 & $0.68-1.53$ & 0.931 \\
\hline \multirow{4}{*}{ GSTO1-C428T (rs4925) } & $\mathrm{CC}$ & $127(67.6 \%)$ & $212(67.3 \%)$ & & & \\
\hline & $\mathrm{CT}$ & $56(29.8 \%)$ & $98(31.1 \%)$ & 1.05 & $0.71-1.56$ & 0.815 \\
\hline & $\mathrm{TT}$ & $5(2.7 \%)$ & $5(1.6 \%)$ & 0.60 & $0.17-2.11$ & 0.420 \\
\hline & $\mathrm{CT}+\mathrm{TT}$ & $61(32.4 \%)$ & $103(32.7 \%)$ & 1.01 & $0.69-1.49$ & 0.954 \\
\hline \multirow[t]{4}{*}{ MTHFR-A1298C (rs1801131) } & $\mathrm{AA}$ & $133(70.7 \%)$ & $224(71.1 \%)$ & & & \\
\hline & $\mathrm{AC}$ & $47(25.0 \%)$ & $80(25.4 \%)$ & 1.01 & $0.67-1.54$ & 0.961 \\
\hline & $\mathrm{CC}$ & $8(4.3 \%)$ & $11(3.5 \%)$ & 0.82 & $0.33-2.08$ & 0.670 \\
\hline & $\mathrm{AC}+\mathrm{CC}$ & $55(29.3 \%)$ & $91(28.9 \%)$ & 0.98 & $0.66-1.46$ & 0.930 \\
\hline \multirow[t]{4}{*}{ DHFR-c594+59del19 } & AA & $22(11.7 \%)$ & $48(15.2 \%)$ & & & \\
\hline & $\mathrm{AG}$ & $81(43.1 \%)$ & $145(46.0 \%)$ & 0.82 & $0.46-1.46$ & 0.498 \\
\hline & GG & $85(45.1 \%)$ & $122(38.7 \%)$ & 0.66 & $0.37-1.17$ & 0.152 \\
\hline & $\mathrm{AG}+\mathrm{GG}$ & $166(88.3 \%)$ & $267(84.7 \%)$ & 0.74 & $0.43-1.27$ & 0.268 \\
\hline \multirow[t]{4}{*}{ TCN2-C776G (rs1801198) } & $\mathrm{CC}$ & $36(19.1 \%)$ & $56(17.8 \%)$ & & & \\
\hline & GC & $100(53.2 \%)$ & $181(57.5 \%)$ & 1.16 & $0.72-1.89$ & 0.540 \\
\hline & GG & $52(27.7 \%)$ & $78(24.8 \%)$ & 0.96 & $0.56-1.67$ & 0.896 \\
\hline & $\mathrm{GC}+\mathrm{GG}$ & $152(80.9 \%)$ & $259(82.2 \%)$ & 1.10 & $0.69-1.74$ & 0.700 \\
\hline \multirow[t]{4}{*}{ TYMS-1494del6 } & $\mathrm{AA}$ & $19(10.1 \%)$ & $34(10.8 \%)$ & & & \\
\hline & $\mathrm{AT}$ & $80(42.6 \%)$ & $148(47.0 \%)$ & 1.03 & $0.55-1.93$ & 0.917 \\
\hline & TT & $89(47.3 \%)$ & $133(42.2 \%)$ & 0.84 & $0.45-1.56$ & 0.570 \\
\hline & $\mathrm{AT}+\mathrm{TT}$ & $169(89.9 \%)$ & $281(89.2 \%)$ & 0.93 & $0.51-1.68$ & 0.808 \\
\hline
\end{tabular}

\section{Compound mutation genotypes}

Compound genotypes were analyzed, including compound mutation genotypes and combined wild-type genotypes. We identified only 1 compound mutation genotype, MTHFDG1958A, MTR-A2756G, and RFC1-G80A, showing a significant difference between preterm and term babies. This value was $7.3 \%$ in preterm babies, which was significantly higher than the value of $2.7 \%$ in term babies, suggesting that the compound mutation genotype $M T H F D$ G1958A, MTR-A2756G, and RFC1-G80A may be a risk factor for PTB (OR $=2.88,95 \% \mathrm{CI}$ 
$=1.08-7.72$, and $\mathrm{P}=0.028$ ). We also found that seven preterm babies carried the compound mutation genotypes, MTHFD-G1958A, MTR-A2756G, and CBS-C699T, but this was not observed in term babies. Although there was no significant difference between preterm and term babies according to the $\chi^{2}$ test with $\mathrm{P}=0.067$, the compound mutation genotype $M T H F D$ G1958A, MTR-A2756G, and CBS-C699T may be a risk factor for PTB given our small sample size. Data regarding other compound mutation genotypes showed no significant differences, but the $\mathrm{P}$ values were close to 0.05 (Table 3 ).

Table 2. Binary logistic analysis.

\begin{tabular}{|c|c|c|c|c|c|c|}
\hline & B & SE & Wald & d.f. & Sig. & $\operatorname{Exp}(B)$ \\
\hline MTHFD-G1958A & -0.089 & 0.151 & 0.346 & 1 & 0.556 & 0.915 \\
\hline MTHFR-C677T & -0.104 & 0.139 & 0.555 & 1 & 0.456 & 0.901 \\
\hline$M T R-\mathrm{A} 2756 \mathrm{G}$ & 0.157 & 0.220 & 0.507 & 1 & 0.476 & 1.170 \\
\hline NFE2L2-ins1C11108T & 0.373 & 0.234 & 2.555 & 1 & 0.110 & 1.453 \\
\hline$M T R R-\mathrm{A} 66 \mathrm{G}$ & -0.148 & 0.156 & 0.906 & 1 & 0.341 & 0.862 \\
\hline$C B S-\mathrm{C} 699 \mathrm{~T}$ & -0.088 & 0.384 & 0.052 & 1 & 0.819 & 0.916 \\
\hline RFC1-G80A & 0.120 & 0.137 & 0.772 & 1 & 0.380 & 1.128 \\
\hline GST01-C428T & -0.024 & 0.182 & 0.017 & 1 & 0.897 & 0.977 \\
\hline MTHFR-A $1298 \mathrm{C}$ & -0.102 & 0.182 & 0.315 & 1 & 0.575 & 0.903 \\
\hline DHFR-c59459del19 & -0.234 & 0.139 & 2.839 & 1 & 0.092 & 0.791 \\
\hline TCN2-C776G & -0.029 & 0.142 & 0.042 & 1 & 0.837 & 0.971 \\
\hline TYMS-1494del6 & -0.136 & 0.145 & 0.879 & 1 & 0.348 & 0.873 \\
\hline Constant & 1.077 & 0.395 & 7.452 & 1 & 0.006 & 2.936 \\
\hline
\end{tabular}

Table 3. Comparison of compound mutation genotypes in preterm and term babies.

\begin{tabular}{|c|c|c|c|c|c|c|}
\hline & \multirow[t]{2}{*}{ Groups } & \multicolumn{2}{|c|}{ Compound mutation genotypes } & \multirow[t]{2}{*}{ OR } & \multirow[t]{2}{*}{$95 \%$ CI } & \multirow[t]{2}{*}{$\mathrm{P}$} \\
\hline & & Yes & No & & & \\
\hline \multirow{2}{*}{ MTHFD-G1958A and MTR-A2756G } & Preterm & 30 & 285 & 2.09 & $0.97-4.51$ & 0.055 \\
\hline & Term & 9 & 179 & & & \\
\hline \multirow[t]{2}{*}{ MTHFD-G1958A, MTR-A2756G and MTHFR-C677T } & Preterm & 20 & 295 & 2.48 & $0.92-6.73$ & 0.065 \\
\hline & Term & 5 & 183 & & & \\
\hline \multirow{2}{*}{ MTHFD-G1958A, MTR-A2756G and NFE2L2-ins1+C11108T } & Preterm & 5 & 310 & 1.50 & $0.29-7.81$ & 0.927 \\
\hline & Term & 2 & 186 & & & \\
\hline \multirow[t]{2}{*}{ MTHFD-G1958A, MTR-A2756G and MTRR-A66G } & Preterm & 15 & 300 & 3.08 & $0.88-10.80$ & 0.109 \\
\hline & Term & 3 & 185 & & & \\
\hline \multirow[t]{2}{*}{ MTHFD-G1958A, MTR-A2756G and CBS-C699T } & Preterm & 7 & 308 & & & 0.067 \\
\hline & Term & 0 & 188 & & & \\
\hline \multirow[t]{2}{*}{ MTHFD-G1958A, MTR-A2756G and RFC1-G80A } & Preterm & 23 & 292 & 2.88 & $1.08-7.72$ & 0.028 \\
\hline & Term & 5 & 183 & & & \\
\hline \multirow[t]{2}{*}{ MTHFD-G1958A, MTR-A2756G and GSTO1-C428T } & Preterm & 13 & 302 & 2.66 & $0.75-9.44$ & 0.193 \\
\hline & Term & 3 & 185 & & & \\
\hline \multirow[t]{2}{*}{ MTHFD-G1958A, MTR-A2756G and MTHFR-A1298C } & Preterm & 13 & 302 & 2.66 & $0.75-9.44$ & 0.193 \\
\hline & Term & 3 & 185 & & & \\
\hline \multirow[t]{2}{*}{ MTHFD-G1958A, MTR-A2756G and DHFR- c594+59del19 } & Preterm & 25 & 290 & 1.94 & $0.86-4.39$ & 0.107 \\
\hline & Term & 8 & 180 & & & \\
\hline \multirow[t]{2}{*}{$M T H F D-\mathrm{G} 1958 \mathrm{~A}, M T R-\mathrm{A} 2756 \mathrm{G}$ and $T C N-\mathrm{C} 776 \mathrm{G}$} & Preterm & 24 & 291 & 2.13 & $0.90-5.05$ & 0.079 \\
\hline & Term & 7 & 181 & & & \\
\hline \multirow[t]{2}{*}{ MTHFD-G1958A, MTR-A2756G and TYMS-1494del6 } & Preterm & 25 & 290 & 2.23 & $0.95-5.26$ & 0.061 \\
\hline & Term & 7 & 181 & & & \\
\hline
\end{tabular}

\section{Combined wild-type genotypes}

No combined wild-type genotypes showed a significant difference in preterm and term babies except the combined wild-type genotype MTHFD-G1958A, MTR-A2756G, MTRRA66G, MTHFR-A1298C, NFE2L2-ins1+C11108T, and RFC1-G80A. Fourteen term babies 
carried the combined wild-type genotype of the total 188 term babies, but only 10 of 315 preterm babies carried this combined wild-type. This indicates that the combined wild-type genotype MTHFD-G1958A, MTR-A2756G, MTRR-A66G, MTHFR-A1298C, NFE2L2-ins1+C11108T, and $R F C 1-\mathrm{G} 80 \mathrm{~A}$ is a protective factor of $\mathrm{PTB}(\mathrm{OR}=0.41,95 \% \mathrm{CI}=0.18-0.94$, and $\mathrm{P}=0.030)$. Babies carrying more wild-type genotypes of the 12 SNPs screened may have a lower risk of PTB and decreased OR values, although not all results showed a significant difference (Table 4).

\begin{tabular}{|c|c|c|c|c|c|c|}
\hline & \multirow[t]{2}{*}{ Groups } & \multicolumn{2}{|c|}{ Combined wild-type genotypes } & \multirow[t]{2}{*}{ OR } & \multirow[t]{2}{*}{$95 \% \mathrm{CI}$} & \multirow[t]{2}{*}{$\mathrm{P}$} \\
\hline & & Yes & No & & & \\
\hline$M T H F D-G 1958 \mathrm{~A}$ and & Preterm & 154 & 161 & 1.21 & $0.84-1.74$ & 0.303 \\
\hline MTR-A2756G & Term & 83 & 105 & & & \\
\hline MTHFD-G1958A, & Preterm & 87 & 228 & 1.03 & $0.68-1.54$ & 0.905 \\
\hline MTR-A2756G and MTRR-A66G & Term & 51 & 137 & & & \\
\hline MTHFD-G1958A, MTR-A2756G, & Preterm & 61 & 254 & 0.87 & $0.55-1.35$ & 0.524 \\
\hline MTRR-A66G, and MTHFR-A1298C & Term & 40 & 144 & & & \\
\hline MTHFD-G1958A, MTR-A2756G, & Preterm & 12 & 303 & 0.49 & $0.22-1.09$ & 0.075 \\
\hline $\begin{array}{l}\text { MTRR-A66G, MTHFR-A } 1298 \mathrm{C} \text {, } \\
\text { and NFE2L2-ins } 1+\mathrm{C} 11108 \mathrm{~T}\end{array}$ & Term & 14 & 174 & & & \\
\hline MTHFD-G1958A, MTR-A2756G, & Preterm & 10 & 305 & 0.41 & $0.18-0.94$ & 0.030 \\
\hline $\begin{array}{l}\text { MTRR-A66G, MTHFR-A } 1298 \mathrm{C} \text {, } \\
\text { NFE2L2-ins1+C11108T and RFC1-G80A }\end{array}$ & Term & 14 & 174 & & & \\
\hline
\end{tabular}

\section{DISCUSSION}

Folic acid is an essential vitamin in cell growth and division, but cannot be synthesized in the human body and thus must be acquired from outside sources. Gene polymorphisms in some enzymes involved in the folate metabolism pathway have been associated with neural tube defects, cardiovascular disease, Down's syndrome, spontaneous miscarriage, lymphocytic leukemia, breast cancer, gastric cancer, and esophageal tumors, Alzheimer's disease, and other diseases (Sharp and Little, 2004). Recently, several studies have demonstrated an association between folate metabolism gene SNPs, and PTB, including the MTHFR-C677T, MTHFR-A1298C, MTR-D919G, MTRR-A66G, and SHMT1-C1420T mutations; however, the results of these studies varied in different ethnic populations (Stonek et al., 2007).

One-carbon metabolism is essential for de novo purine and thymidylate (dTMP) synthesis and for the remethylation of homocysteine to methionine, which can be adenosylated to form the universal methyl donor $S$-adenosylmethionine. One-carbon metabolism can be impaired by genetic variation, nutrient deficiencies, or both, which can simultaneously disrupt de novo nucleotide biosynthesis and $S$-adenosylmethionine synthesis to result in reduced proliferative capacity, increased uracil in DNA, elevated plasma homocysteine, and reduced cellular methylation (Stover, 2004; Beaudin et al., 2011).

Here, we report the association between SNPs in one-carbon metabolism-related genes and PTB in China. Twelve SNPs from 11 candidate genes involved in folate metabolism were screened to identify associations with PTB in 315 newborn preterm babies and 188 term babies using the SNaPshot method, including MTR-A2756G, MTRR-A66G, DHFR-c594+59del19, MTHFR-C677T, and -A1298C, CBS-C699T, GST01-C428T, MTHFD1-G1958A, NFE2L2ins1+C11108T, RFC1-G80A, TCN2-C776G, and TYMS-1494del6.

$M T H F R$ is the gene most implicated as being related to the folate metabolism pathway, 
which was reported in the association with PTB. MTHFR is a rate-limiting enzyme involved in folate metabolism and catalyzes the conversion of $\mathrm{N}^{5}, \mathrm{~N}^{10}$-methylenetetrahydrofolate into $\mathrm{N}^{5}$-methyltetrahydrofolate, which is converted to homocysteine and methionine. The human gene encoding $\mathrm{N}^{5}, \mathrm{~N}^{10}$-methylenetetrahydrofolate reductase is located on chromosome $1 \mathrm{p} 36.3$, and nearly 20 mutations in MTHFR genes have been identified; the most common MTHFR mutations include C677T (valine $\rightarrow$ alanine) and A1298C (glutamate $\rightarrow$ alanine), which lead to reduced enzyme activity (van der Put et al., 1998). Previous studies have found that the MTHFR-C677T mutation may increase the demand of folic acid, particularly during the fetal growth period, which may cause a relative lack of folic acid. Good nutrition can reduce elevated hyperhomocysteinemia caused by mutations in the MTHFR gene. MTHFR-C677T and $M T H F$-A1298C showed only a minimal association with preterm delivery in both whites and blacks (Engel et al., 2006; Gargano et al., 2009) as well as in cases in Turkey (Uvuz et al., 2009) in some studies. Gargano also studied 560 whites and 399 blacks and showed that MTHFR-C677T and MTHFR-A1298C were only correlated with the placental-type premature birth, but had no correlation with the other types of premature births. Stonek et al. (2007) prospectively studied 1675 MTHFR-C677T carriers using DNA microarray and found that $16.6 \%$ of 278 women developed had at least one mutant phenotype (intrauterine demise, preeclampsia, premature delivery, and fetal growth less than a week of pregnancy) and concluded that MTHFR-C677T may be a genetic marker for fetal development that does not reach gestational age. Chen et al. (2004) reported that the MTHFR CT genotype and TT genotype may significantly increase the risk of preterm birth and low birth weight in Chinese people, compared with the MTHFR CC genotype when children' genotypes were considered; these results were statistically significant. The MTHFR gene polymorphism was not associated with preterm birth and low birth weight when mothers' genotypes were considered. Additionally, the study found no significant interaction between mothers' and childrens' genotypes with the risk of preterm birth and low birth weight. Furthermore, MTHFR (677) T mutant alleles in preterm core pedigrees did not agree with Mendel's laws of inheritance, and may be genetic susceptibility loci causing premature birth. In addition, the MTHFR gene may lead to low birth weight through gestational week shortening when delivery is premature (Chen et al., 2004). We found that 1 site or a combination of 2 sites were weakly correlated with preterm birth. MTHFR C677T and A1298C polymorphisms have been examined in various studies of genetic variation involved in folate metabolis. However, the results were conflicting, with some studies reporting protective effects for MTHFR-677TT (Skibola et al., 2002) and -1298 CC, whereas others, including this study, yielded little or no evidence of an effect of MTHFR-C677T and -A1298C (Gargano et al., 2009). There are several possible reasons for these inconsistencies, such as the small case population used in many previous studies. Additionally, different standards were used to select the control groups. Finally, the complexity of the folate metabolism pathway may have resulted in inconsistencies.

In addition to MTHFR-C677T and A1298C, MTR-A2756G, MTRR-A66G, and $D H F R$-c594+59del19 are also interesting as candidate genes.

Methyltransferase/methionine synthase catalytic homocysteine methylation generate methionine and reduce to $S$-adenosylmethionine, which donates a methyl group in vivo. The gene coding methionine synthase is located on chromosome 1q43. MTR-A2756G (glycine $\rightarrow$ aspartic acid) is located in the domain relevant to vitamin $B_{12}$ cofactor methylation, and reactivation and mutations can lead to changes in enzymatic activity, which affects the DNA methylation status and downstream gene expression. Beaudin et al. (2012) found no 
association between MTR-A2756G and preterm birth in both white and black subjects. In our study, we found a correlation between MTR-A2756G and PTB in Chinese subjects. Results from Chinese people are coincident with that found in the white and black populations.

Methionine synthase reductase (MTRR) can reduce the activity of methyltransferase, a cofactor of methionine synthase that can maintain methionine synthase activity through cobalamin interactions. MTRR plays an important role in converting homocysteine to methionine, DNA methylation, and biosynthesis. The gene coding methionine synthase reductase is located on chromosome $5 \mathrm{p} 15.31$. Currently, studies examining polymorphisms in the MTRR gene focus on MTRR-A66G (isoleucine $\rightarrow$ methionine), which decreases enzyme activity, alters folate metabolism, and affects DNA synthesis and methylation. Wilson et al. (1999) reported that the MTRR-A66G polymorphic locus increased the risk of neural tube defects by 5 -fold when drill amine hormone levels were low or in the presence of combined MTHFR and MTRR homozygous mutant genotypes. Engel et al. (2006) reported that MTRR-A66G increased the spontaneous preterm birth risk in white subjects, which appeared to be unrelated to folic acid supplementation, while in black subjects, the MTRR-A66G genotype was unrelated to the risk of preterm birth. However, we found a weak correlation between MTRR-A66G and preterm birth in Chinese subjects.

Dihydrofolate reductase (DHFR) can catalyze the reduction of tetrahydrofolic acid. The gene encoding DHFR is located on chromosome $5 \mathrm{q} 14.1$ and contains a common polymorphism in intron 1 of a 19-bp deletion, preventing the interaction between the specificity protein 1 transcription factor; intron 1 of many genes is typically a regulatory sequence (Kaneda et al., 1992; Takayanagi et al., 1992; Guérin et al., 1995; Clark et al., 1997). Johnson et al. (2005) studied 324 pregnant women in the impoverished area of Camden, NJ, in the US. Women with a DHFR gene deletion allele showed a significantly higher risk of preterm delivery (adjusted $\mathrm{OR}=3.0)$ compared to women without a deletion allele. Women with both a DHFR deletion allele and low folate intake ( $<400 \mathrm{~g}$ /day from diet plus supplements) showed a significantly higher risk of preterm delivery and significantly higher risk of delivering an infant with a low birth weight compared to women without a deletion allele and with folate intake $\geq 400 \mathrm{~g}$ /day (Johnson et al., 2005). This polymorphism can reduce the transcription and transportation of folic acid to the fetus. When the intron 1 is present in the Chinese hamster ovary cells, DHFR is higher than that of intron deletion cells, and the protein encoded by the intronless construct is unstable because of lysosomal degradation. Therefore, the DHFR 19-bp deletion allele may be a risk factor for preterm delivery, which may depend on gene-environment interactions (Johnson et al., 2005). However, we found a weak correlation between the DHFR 19-bp deletion and preterm birth in the Chinese population.

The association between 7 other SNPs, including CBS-C699T, GST01-C428T, MTHFD1G1958A, NFE2L2-ins1+C11108T, RFC1-G80A, TCN2-C776G, and TYMS-1494del6, and preterm birth has not been previously reported. Because these SNPs are important in the folic acid metabolic pathway (Shaw et al., 2009), we analyzed the correlation between these SNPs and preterm birth, but only observed weak correlations in the Chinese population.

Compound genotypes were also analyzed in our study. We found that the compound mutation genotypes MTHFD-G1958A, MTR-A2756G, and RFC1-G80A increased the risk of preterm birth $(\mathrm{OR}=2.88,95 \% \mathrm{CI}=1.08-7.72, \mathrm{P}=0.028)$. We found that 7 preterm babies carried the compound mutation genotype MTHFD-G1958A, MTR-A2756G, and CBS-C699T, but this compound genotype was not present in term babies. Because of the small size sample in our study, this compound mutation genotype may be another risk factor for preterm birth. In 
addition to the 2 risk factors, we also found that the combined wild-type genotype $M T H F D$ G1958A, MTR-A2756G, MTRR-A66G, MTHFR-A1298C, NFE2L2-ins1+C11108T, and $R F C 1$-G80A decreased the risk of preterm birth $(\mathrm{OR}=0.41,95 \% \mathrm{CI}=0.18-0.94, \mathrm{P}=0.030)$, and a larger number of wild-type genotypes further lowered the risk of preterm birth, although the difference was not always significant. It was unclear why the 12 SNPs were not independent risk or protective factors, while compound mutations or combined wild-type genotypes increased or decreased the risk of preterm birth. This may be because the folic acid metabolic pathway is very complicated and methods for compensating for deficiencies exist; folic acid metabolism disorder by one or more genetic mutations may be repaired through compensating pathways and folic acid supplementation (Bodnar et al., 2010; Wang and Chen, 2012).

Although molecular epidemiological studies have confirmed that some of the factors described in this study lead to a high risk of preterm birth, the causes of most cases of preterm labor are unknown and the potential pathogenic mechanisms of preterm birth require further study. Genetic susceptibility is an important factor leading to premature delivery and may synergistically function with environmental factors. The clinical phenotype caused by genetic mutations related to the folate metabolism pathway depends on individual folic acid intake, and thus folic acid supplementation can prevent some cases of preterm delivery. Studies involving a larger sample size of PTBs and controls are underway to validate the potential application of these loci as clinical biomarkers for prenatal screening to determine the risk of PTB in a longitudinal cohort study.

\section{ACKNOWLEDGMENTS}

Research supported in part by the "Twelfth Five" Key Medical Talent's Project in Science and Education of Jiangsu Province (\#RC2011036), grant of the Natural Science of Jiangsu Province (\#BK2012600), the Suzhou Science and Technology Development Project (\#SZD0891), and the Suzhou Key Lab of Translational Medicine Project (\#SZS201206).

\section{REFERENCES}

Bardien S, Human H, Harris T, Hefke G, et al. (2009). A rapid method for detection of five known mutations associated with aminoglycoside-induced deafness. BMC Med. Genet. 10: 2-10.

Beaudin AE, Abarinov EV, Noden DM, Perry CA, et al. (2011). Shmt1 and de novo thymidylate biosynthesis underlie folate-responsive neural tube defects in mice. Am. J. Clin. Nutr. 93: 789-798.

Beaudin AE, Abarinov EV, Malysheva O, Perry CA, et al. (2012). Dietary folate, but not choline, modifies neural tube defect risk in Shmt1 knockout mice. Am. J. Clin. Nutr. 95: 109-114.

Bodnar LM, Himes KP, Venkataramanan R, Chen JY, et al. (2010). Maternal serum folate species in early pregnancy and risk of preterm birth. Am. J. Clin. Nutr. 92: 864-871.

Bukowski R, Malone FD, Porter FT, Nyberg DA, et al. (2009). Preconceptional folate supplementation and the risk of spontaneous preterm birth: a cohort study. PLoS Med. 6: e1000061.

Chen DF, Hu YH, Yang F, Wu BY, et al. (2004). Mother's and child's methylenetetrahydrofolate reductase C677T polymorphism is associated with preterm delivery and low birth weight. Beijing Da Xue Xue Bao 36: 248-253.

Clark IM, Rowan AD, Edwards DR, Bech-Hansen T, et al. (1997). Transcriptional activity of the human tissue inhibitor of metalloproteinases 1 (TIMP-1) gene in fibroblasts involves elements in the promoter, exon 1 and intron 1. Biochem. J. 324: 611-617.

Engel SM, Olshan AF, Siega-Riz AM, Savitz DA, et al. (2006). Polymorphisms in folate metabolizing genes and risk for spontaneous preterm and small-for-gestational age birth. Am. J. Obstet. Gynecol. 195: 1231.e1-11.

Gargano JW, Holzman CB, Senagore PK, Reuss ML, et al. (2009). Polymorphisms in thrombophilia and renin-angiotensin system pathways, preterm delivery, and evidence of placental hemorrhage. Am. J. Obstet. Gynecol. 201: 317.e1-9.

Guérin SL, Leclerc S, Verreault H, Labrie F, et al. (1995). Overlapping cis-acting elements located in the first intron of 
the gene for type I 3 beta-hydroxysteroid dehydrogenase modulate its transcriptional activity. Mol. Endocrinol. 9: 1583-1597.

Han YS, Ha EH, Park HS, Kim YJ, et al. (2011). Relationships between pregnancy outcomes, biochemical markers and pre-pregnancy body mass index. Int. J. Obes. 35: 570-577.

Johnson WG, Scholl TO, Spychala JR, Buyske S, et al. (2005). Common dihydrofolate reductase 19-base pair deletion allele: a novel risk factor for preterm delivery. Am. J. Clin. Nutr. 81: 664-668.

Kaneda S, Horie N, Takeishi K, Takayanagi A, et al. (1992). Regulatory sequences clustered at the 5' end of the first intron of the human thymidylate synthase gene function in cooperation with the promoter region. Somat. Cell. Mol. Genet. 18: 409-415.

Sharp L and Little J (2004). Polymorphisms in genes involved in folate metabolism and colorectal neoplasia: a HuGE review. Am. J. Epidemiol. 159: 423-443.

Shaw GM, Lu W, Zhu H, Yang W, et al. (2009). 118 SNPs of folate-related genes and risks of spina bifida and conotruncal heart defects. BMC Med. Genet. 10: 49.

Skibola CF, Smith MT, Hubbard A, Shane B, et al. (2002). Polymorphisms in the thymidylate synthase and serine hydroxymethyltransferase genes and risk of adult acute lymphocytic leukemia. Blood 99: 3786-3791.

Sonne SR, Bhalla VK, Barman SA, White RE, et al. (2013). Hyperhomocysteinemia is detrimental to pregnancy in mice and is associated with preterm birth. Biochim. Biophys. Acta 1832: 1149-1158.

Stonek F, Hafner E, Philipp K, Hefler LA, et al. (2007). Methylenetetrahydrofolate reductase C677T polymorphism and pregnancy complications. Obstet. Gynecol. 110: 363-368.

Stover PJ (2004). Physiology of folate and vitamin B12 in health and disease. Nutr. Rev. 62: S3-S12; discussion S13.

Takayanagi A, Kaneda S, Ayusawa D and Seno T (1992). Intron 1 and the 5'-flanking region of the human thymidylate synthase gene as a regulatory determinant of growth-dependent expression. Nucleic Acids Res. 20: 4021-4025.

Uvuz F, Kilic S, Yilmaz N, Tuncay G, et al. (2009). Relationship between preterm labor and thrombophilic gene polymorphism: A prospective sequential cohort study. Gynecol. Obstet. Invest. 68: 234-238.

Valdez LL, Quintero A, Garcia E, Olivares N, et al. (2004). Thrombophilic polymorphisms in preterm delivery. Blood Cells Mol. Dis. 33: 51-56.

van der Put NM, Gabreëls F, Stevens EM, Smeitink JA, et al. (1998). A second common mutation in the methylenetetrahydrofolate reductase gene: an additional risk factor for neural-tube defects? Am. J. Hum. Genet. 52: 1044-1051.

Wang BJ and Chen Y (2012). Folic acid metabolism gene polymorphism and congenital heart disease. Zhonghua Er Ke Za Zhi 50: 630-633.

Wang B, Liu M, Yan W, Mao J, et al. (2013). Association of SNPs in genes involved in folate metabolism with the risk of congenital heart disease. J. Matern. Fetal Neonatal Med. 26: 1768-1777.

Wilson A, Platt R, Wu Q, Leclerc D, et al. (1999). A common variant in methionine synthase reductase combined with low cobalamin (vitamin B12) increases risk for spina bifida. Mol. Genet. Metab. 67: 317-323.

Wu CC, Lu YC, Chen PJ, Liu AY, et al. (2009). Application of SNaPshot multiplex assays for simultaneous multigene mutation screening in patients with idiopathic sensorineural hearing impairment. Laryngoscope 119: 2411-2416. 